has not read Russell's Oak Ridge Symposium volume, Genetic Mosaics and Chimeras in Mammals (Plenum, 1980), nor the more recent work with fetal mouse hermaphrodites. These topics really deserved a chapter by Beamer whose BALB/CBea mice generate mosaic hermaphrodites by nondisjunction, or Eicher who has transferred the Y-chromosome of Mus poschiavinus to C57BL/6J-YPOS. This chromosome carries a variant of the testis-determination locus which interacts abnormally with autosomal or X-linked loci preventing normal testis differentiation even in the presence of $\mathrm{H}-\mathrm{Y}$ antigen. Also there are excellent controls from consomic strains for these interesting animals.

The words "mechanisms" and "animals" in the title are misleading because some chapters, such as Stevens's account of his exciting spontaneous and induced teratomas, are purely descriptive, and except for a few pages of introduction and an excellent contribution on environmental and non-genetic mechanisms the book is restricted to mammals.

Reviewing this book has been difficult because many of the references cited, including books, are recent and not freely available in libraries with restricted budgets. There is no author index and the inadequate subject index appears to have been compiled from the table of contents. An editorial policy of giving the specific name when a species is first mentioned would have ensured entries for "'man"' and "mouse", at least in the species index, and eliminated some redundant ones. Surely textbooks warrant the services of professional indexers?

The editors consider the possibility of voluntary control of sex determination and doubt the "dire prognostications" that acquisition of this knowledge would upset the "fabric of society". Instead, they predict smaller, planned families and elimination of sex-linked disease, but conclude that no foolproof method exists at present. Already blastocysts can be sexed before implantation and fetuses of the unwanted sex aborted. Ironically, the early data from test-tube babies gave an excess of females $(P<0.03)$ which might have been interpreted to mean that a procedure favouring girls had been stumbled upon. But $\mathrm{I}$ believe that biologists generally should require a probability of less than 0.01 before assigning significance, and this conviction has been supported by more recent results, particularly from Melbourne.

In spite of these criticisms I consider this a valuable and major work, updating Crew's little gem Sex Determination, published by Methuen in 1965, and fit to stand alongside White's Animal Cytology and Evolution (Rand McNally, 1973).

W.K. Whitten is a Research Associate in the Department of Zoology, University of Tasmania.

\title{
News of conception, pure and applied
}

\section{C.R. Austin}

Fertilization and Embryonic Development in Vitro. Edited by Luigi Mastroianni and John D. Biggers. Pp.371. ISBN 0-306-40783-3. (Plenum: 1981.) \$45, $£ 28.35$. In Vitro Fertilization and Embryo Transfer. Edited by E.S.E. Hafez and K. Semm. Pp.393. UK ISBN 0-85200-438-9; US ISBN 0-8451-3005-6. (MTP Press/Alan R. Liss: 1982.) $£ 29.95, \$ 58$.

THE recent upsurge of attention paid in the public media to the growing number of normal childbirths following the fertilization of human eggs in vitro, and the culture and reinsertion of the resulting embryos into their "'mothers", must serve as welcome publicity for these two books, both of which provide in their own way the background to those newsworthy events. The publicity is a late development, for the vigour of scientific research in this field has been building up for the past 25-30 years, and the intellectual springs behind this drive are based on biologists' ambitions that go back a century or more.

Some of the history is discussed in the Prologue to the book edited by Mastroianni and Biggers, though this account is concerned primarily with milestones along the trail of the recovery and culture of mammalian embryos. From early times, investigators have been fascinated by the prospect that conditions might be achieved in the laboratory permitting the union of mammalian gametes and the ensuing development of the embryos in such a way that these events could be held under direct observation in vitro. Also early in the story, the remarkable resilience of mammalian embryos to experimental manipulation attracted devoted study, and the first successes with the transfer of embryos from one animal to another were achieved before the turn of the century. With increasing sophistication the focus has sharpened in the modern era so that investigators have become concerned more and more with fundamental details.

The two books under review have, not surprisingly, much in common. They are of about the same vintage, with that edited by Hafez and Semm marginally the older as it is based on papers presented at a world conference in 1980 . The other is a "planned" book of 15 chapters (21 authors, all in American laboratories), while Hafez and Semm is comprised of 37 papers (71 authors, of whom 51 work in countries other than the USA, chiefly West Germany, France and Japan). The common ground of subject matter includes the recovery and preparation of gametes, in vitro fertilization, the culture and evaluation of embryos, and embryo transfer; differences arise from the manner in which the subjects are handled and in the identity of peripheral topics. Broadly speaking, Mastroianni and Biggers is biased towards basic problems and $\mathrm{Hafez}$ and Semm towards the applied.

The former volume is distinguished by a monumental chapter by $\mathbf{R}$. Yanagimachi on mechanisms of fertilization in mammals; this, together with three others (by G. Oliphant and L. A. Eng, B. D. Bavister, and D. P. Wolf), tells the reader almost all there is need to know about sperm maturation and capacitation, the acrosome reaction, penetration of egg investments, sperm-egg fusion, pronuclear life and the blocks to polyspermy - all this in laboratory animals. In vitro techniques are stressed. In addition, this book offers two chapters on gamete interactions and egg activation in the sea urchin (a worthy comparative background, though inessential in the present context), two chapters on chromosomal anomalies affecting embryonic development, two more on the rather esoteric topic of water and electrolyte balances in blastocysts, and finally a well planned and informative chapter on embryo transfer in cattle.

In Hafez and Semm, by contrast, no less than 14 papers describe the application of methods for in vitro fertilization, and four deal with embryo transfer. About half the papers in this book accord at least a mention to the human subject, for whom the timing of ovulation, oocyte recovery and maturation in vitro, fertilization in vitro and embryo evaluation are treated in varied but generally satisfactory detail, and the ethics of embryo transfer are briefly discussed. Curiously, none of the research groups that have reported full success with human material - well established pregnancies and normal births - are represented here. Other papers are concerned with non-human primates and farm animals. The book also fortunately provides us with Pierre Soupart's report, bringing us up to date with his work on initiating development by the singular device of fusing two oocytes; this may have been his last paper. In addition, there is a report on gonadotrophin production by baboon embryos in vitro from V.Z. Pope et al., and descriptions of two recently developed rapid assay methods for $\mathrm{LH}$ by $\mathrm{M}$. Taymor et al. and by R. Frydman et al.

Both of these books are mines of information and "musts", for all gametologists; if only one is to be purchased the choice must depend on the predilection of the reader - whether for the basic or the applied, for the transatlantic or the international, or simply for the more or less expensive.

C.R. Austin is Emeritus Charles Darwin Professor of A nimal Embryology, University of Cambridge. 